\title{
Estimating deformation due to soil liquefaction in Urayasu city, Japan using permanent scatterers
}

\author{
$\operatorname{AUTHOR}(\mathrm{S})$ :
}

ElGharbawi, Tamer; Tamura, Masayuki

\section{CITATION:}

ElGharbawi, Tamer ...[et al]. Estimating deformation due to soil liquefaction in Urayasu city, Japan using permanent scatterers. ISPRS Journal of Photogrammetry and Remote Sensing 2015, 109: 152-164

\section{ISSUE DATE:}

2015-11

URL:

http://hdl.handle.net/2433/203036

\section{RIGHT:}

(c) 2015. This manuscript version is made available under the CC-BY-NC-ND 4.0 license

http://creativecommons.org/licenses/by-nc-nd/4.0/; The full-text file will be made open to the public on 1 November 2017 in accordance with publisher's 'Terms and Conditions for Self-Archiving'.; This is not the published version. Please cite only the published version.; この論文は出版社版でありません。引用の際には出版社版をご磪認じ利用ください。 


\title{
Estimating Deformation Due To Soil Liquefaction in Urayasu City, Japan Using Permanent Scatterers
}

\begin{abstract}
In Japan, several cities endured severe damage due to soil liquefaction phenomenon, which was developed in association with the massive shaking of the 2011 Tohoku earthquake. Measuring soil liquefaction deformations was not an easy task, mainly because of the total loss of signal coherence in the affected regions. In this paper, we present our approach to estimate the deformations associated with soil liquefaction using interferometric synthetic aperture radar techniques. We use a stack of coseismic interferograms to identify the reliable pixels in the damaged areas using permanent scatterers technique. Then, we estimate and remove the preseismic mean velocity and DEM error components. Finally, we identify the liquefaction deformation component using least squares inversion and spatial phase filtering. We test the performance of the proposed approach using synthetic data, simulating the effects of soil liquefaction. The simulation results show a RMSE of the liquefaction deformation of $5.23 \mathrm{~mm}$. After that, we estimate the deformation associated with soil liquefaction in Urayasu city, Japan, using ALOS-PALSAR data. The proposed approach allows a prompt estimation of the liquefaction deformation by utilizing the SAR images archives with only one postseismic SAR image.
\end{abstract}

\section{Keywords}

2011 Tohoku Earthquake; Liquefaction Deformation; Urayasu City; Permanent Scatterers; InSAR.

\section{Introduction}

The 2011 off the Pacific Coast Tohoku earthquake is the largest earthquake recorded in the history of seismic observation in Japan. This megathrust earthquake struck Japan with a moment magnitude of M9.0 on March 11, 2011 at 05:46 Universal Time Coordinated (UTC). Destructive damage was caused by this earthquake and by the tsunami which followed it, along the Pacific Coast in Tohoku and Kanto, Japan. Imakiire and Kobayashi (2011) presented the coseismic displacement maps for Japan using GNSS Earth Observation Network System’s (GEONET). The coseismic crustal deformation was remarkably large with a maximum horizontal onshore movement of 5.3 meters and a subsidence of 1.2 meters. Regarding Kanto region, ElGharbawi and Tamura (2014) used InSAR and GPS observations to present the coseismic crustal deformation for Tokyo bay area showing a maximum displacement of 0.8 meters in the Line-Of-Sight (LOS) direction. In addition to this large crustal motion, extensive soil liquefaction was developed causing severe damage to the super and infrastructures over a wide area along the Pacific Coast in Tohoku and in Kanto, including the Tokyo Bay area. Numerous researchers reported their field investigation results of the local surface deformations due to soil liquefaction in Kanto region (Bhattacharya et al., 2011; Yamaguchi et al., 2012; Yasuda et al., 2012; Tokimatsu et al., 2012; Tsukamoto et al., 2012; Ishihara, 2012).

Because of the extensive damage that was caused by soil liquefaction, the need for deformation assessment in liquefied areas has been raised. Interferometric synthetic aperture radar (InSAR) has been used successfully to measure and study surface deformation due to several phenomena (Burgmann et al., 2000) such as glacier movements (Goldstein et al., 1993), earthquakes (Massonnet et al., 1994) and land subsidence (Buckley et al., 2003). Unfortunately, because of the total loss of coherence in liquefied areas the standard multi-look InSAR analysis techniques could not be successfully applied. Furthermore, it is rather unconventional to use single-look (Permanent Scatterers) InSAR techniques in major shock earthquake deformation analysis. Nevertheless, it is very tempting to investigate the possibility of using Permanent Scatterers InSAR (PS-InSAR) techniques to estimate liquefaction deformation because of its numerous advantages.

The Permanent Scatterers (PSs) was first introduced by Ferretti et al. (2001) which refers to those pixels that maintain coherent over long time intervals. The PS pixels are less affected by temporal and geometrical decorrelations, therefore, PS pixels are very good targets for InSAR time series analysis. Using PS pixels in deformation time series analysis was a breakthrough that led to increasing the accuracy of estimated terrain velocity and Digital Elevation Model (DEM) up to millimeter and submeter level, respectively. Several researchers developed valuable methods to identify and analyze PS pixels e.g., (Ferretti et al., 2001; Ferretti et al., 2000; Lyons et al., 2003; Kampes, 2005). These methods use a functional model to describe the temporal variation of the phenomenon that being analyzed which have been very successful in deformation monitoring in urban areas. For rural areas, Hooper et al. (2007) developed a method named StaMPS for identifying and analyzing PS pixels. 
They proposed using temporal phase analysis to estimate the phase stability of the candidate pixels, then isolating the PS pixels based on probability estimation. Finally, they estimated the deformation signal by phase unwrapping and subtracting estimates of the nuisance terms.

PS-InSAR techniques mainly estimate the mean crustal deformation velocity. For temporal non-linear deformation analysis, an estimate of the mean deformation velocity has to be conducted first. Then the residual phases are subjected to additional analysis process, such as, applying spatial and temporal filtering (Ferretti et al., 2000), Single Value Decomposition (SVD) analysis (Mora et al., 2003) or empirical mode decomposition analysis (Liu et al., 2009). The main target of this paper is estimating the deformation associated with soil liquefaction in Urayasu city Japan, but the liquefaction phenomenon was developed in association with the massive shaking of the 2011 Tohoku earthquake, therefore it is a discrete event and can only be analyzed using a preseismic SAR image and postseismic one to form a coseismic interferogram. Unfortunately, due to the severe damage associated with liquefaction the interferogram phases appear to be decorrelated. Furthermore, the coseismic shock of the 2011 Tohoku earthquake (Imakiire and Kobayashi, 2011; ElGharbawi and Tamura, 2014) prevents an adequate estimation of the mean temporal velocity using PS-InSAR technique, even for correlated pixels.

In this paper, we describe our approach to estimate the deformation associated with soil liquefaction in Urayasu city, Japan, one of the severely affected regions by this phenomenon. The main importance of this analysis comes from that, it is very difficult to retrieve deformations due to soil liquefaction using multi-look InSAR analysis because the loss of coherence in the liquefied areas, furthermore, the soil liquefaction phenomenon can be a real hazard in seismic active regions like Japan.

Before proceeding with deformation analysis, we first conduct a simulation analysis for PS behavior in liquefied regions. The target of this simulation is to assure the reliability of using PS pixels in this type of analysis. After the simulation, we start our analysis by generating a stack of single master interferograms. We use a postseismic image as a master and a stack of preseismic images as slaves. In this interferometric stack the coseismic shock of the earthquake is presented in every interferogram and the near linear velocity requirement for PS analysis is preserved. Then, we select an initial pixels subset based on amplitude analysis and refine that selection by estimating the temporal phase stability. After that, we use a functional model to estimate the relative mean velocity and DEM error between neighboring pixels. After removing the estimated parameters from the observed phases, we identify the master image contribution, which contains the liquefaction effect among others. Finally, to isolate the liquefaction effect, we apply spatial filtering to the master contribution using only the pixels that are located in non-liquefied areas.

In this paper, we prove that PS analysis can be applied successfully in areas affected by major earthquakes like the 2011 Tohoku earthquake. Also, we identify reliable pixels within heavily damaged areas due to soil liquefaction phenomenon. We estimate and remove the effects of preseismic mean velocity and DEM error from the PSs observed phase. And finally, we present the deformation due to soil liquefaction effect in Urayasu city, Japan. We test our approach using synthetic data then we apply it to our study area using ALOS-PALSAR data.

This paper is organized as follows: Section 2 describes the study area and liquefaction effect on InSAR analysis. Section 3 presents the analysis approach. Section 4 presents the application of the proposed method using synthetic. Section 5 presents the estimation of liquefaction deformation in Urayasu city and finally section 6 is dedicated to conclusions.

\section{Study Area and Problem Identification}

\subsection{Study Area and Data Used}

Urayasu city, Japan (Fig. 1) was built on reclaimed land during the 1960’s to 1980's (Tokimatsu et al., 2012). During the 2011 Tohoku earthquake, the city suffered from severe damage due to soil liquefaction, this damage was reported by Kanto Regional Development Bureau (KRDB) and the Japanese Geotechnical Society (JGS) (Fig. 2.c). The deformation associated with soil liquefaction effect in Urayasu city is the main focus of this analysis; therefore, the study area was restricted to $11.4 \times 9.6 \mathrm{~km}$ in range and azimuth directions, respectively. In this analysis, we use 18 ALOS-PALSAR, ascending, SAR images spanning from August 8, 2006 to April 6, 2011 (Table 2). For our study area, only one postseismic image is available, because ALOS-PALSAR went out of service shortly after the main shock of the 2011 Tohoku earthquake. 


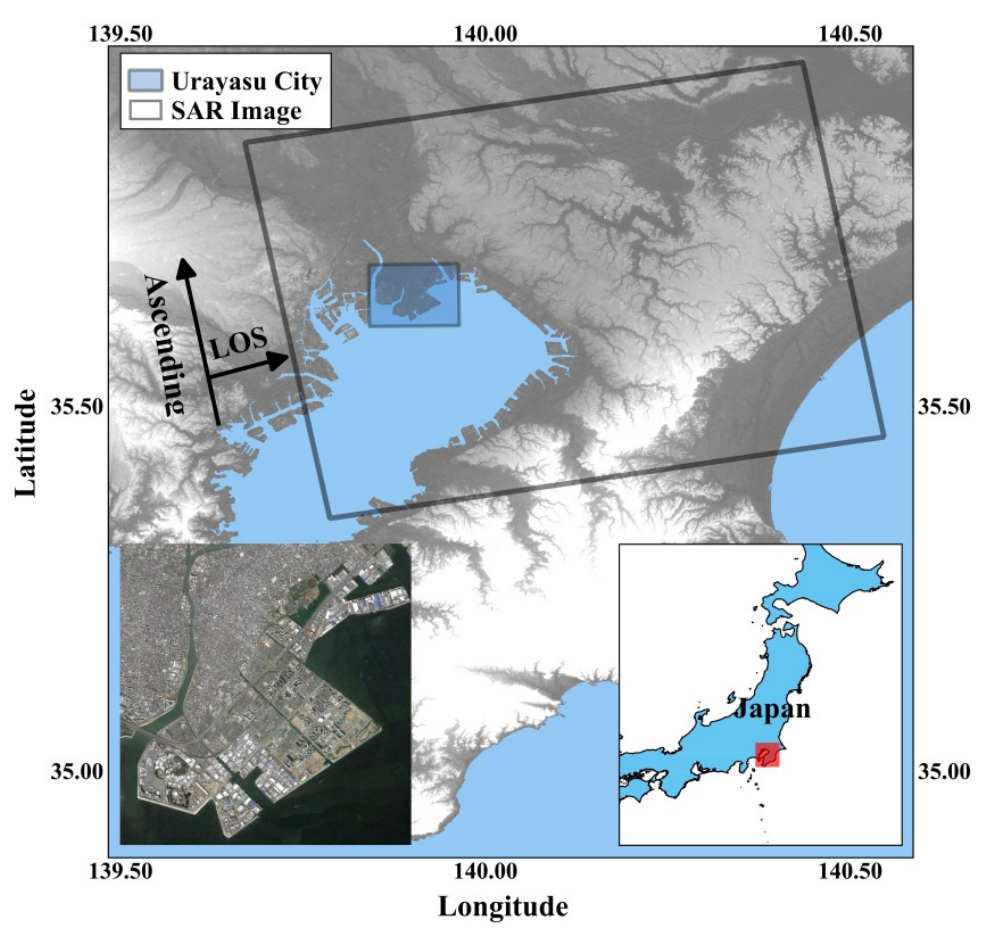

Fig.1. Urayasu city, Kanto region , Japan. Arieal image from Google Earth.

\subsection{Problem Identification}

The main problem in measuring the deformation associated with soil liquefaction is the total loss of coherence in the affected areas. This coherence loss inspired Ishitsuka et al., (2012) and Tamura and Li, (2013) to identify the pixels that were affected by soil liquefaction by subtracting a preseismic coherence map from the coseismic coherence map then setting a suitable threshold. Nevertheless, a measure of the deformation associated with soil liquefaction could not be estimated using InSAR technique yet.

To demonstrate the severity of the problem, we generate a preseismic coherence map using two ALOSPALSAR images acquired on January 4, 2011 and February 19, 2011 (Fig. 2.a). We also generate a coseismic coherence map using images acquired on February 19, 2011 and April 6, 2011 (Fig. 2.b). A comparison between these two figures demonstrates the liquefaction damage extent and severity around Tokyo bay area. The Kanto Regional Development Bureau (KRDB) and the Japanese Geotechnical Society (JGS) conducted an extensive field survey to map the damaged areas due to soil liquefaction (Fig. 2.c). The surveyed areas were classified to (Liquefaction place) and (Non-liquefaction place).And because of the laboring surveying process, some assumptions had to be made to save time and resources, therefore, additional categories were added to the classification, (Assumed liquefaction area) and (Assumed non-liquefaction area). By comparing the coseismic coherence map (Fig. 2.b) and the field survey map (Fig. 2.c), a good agreement can be observed. 

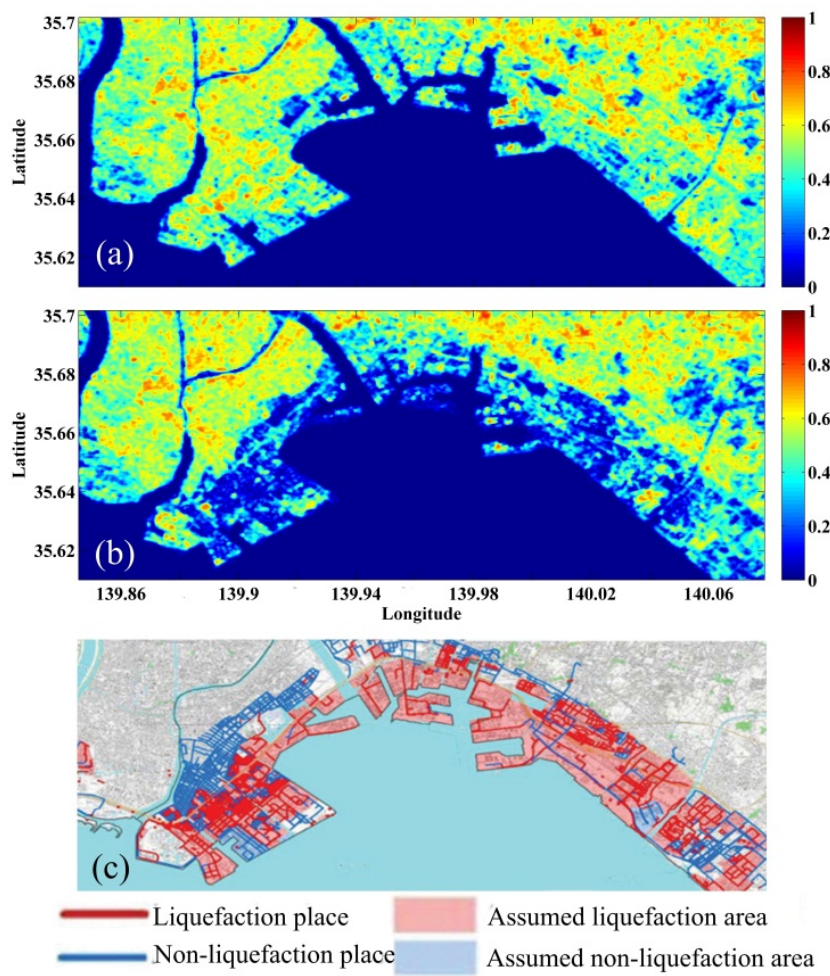

Fig.2. (a) Preseismic coherence map [January 4, 2011- February 19, 2011], (b) Coseismic coherence map [February 19, 2011- April 6, 2011] and (c) Field survey for liquefaction areas conducted by KRDB and JGS (2011).

\subsection{Permanent Scatterers in Liquefied Regions.}

We study the coherence, $\gamma_{c}$, and temporal correlation, $\gamma_{t}$, for PS pixels that were affected by soil liquefaction using simulation analysis. The target of this simulation is to prove that, in areas that were subjected to large deformation causing total coherence loss, PSs can still be identified and provide valuable information.

To study the coherence eq. (1.a) (Guarnieri and Prati, 1997) and temporal correlation eq. (1.b) (Ferretti et al., 2001) simultaneously, we simulate 31 SAR images with dimensions of 8-by-3 pixels. For every pixel in the simulated images, we assume that it contains a number of scatterers, and the final observed phase for each pixel is the summation of the complex return of all the scatterers contained in that pixel. We assume that every pixel contains only one dominating scatterer (a PS) and five dominated scatterers (Fig. 3.a).

The complex observation of each pixel can be simulated by eq. (1.c). In this simulation, we assign the magnitude of the dominated scatterers as one-tenth the magnitude of the dominating scatterer (PS). To simulate the situation before the earthquake, we assume a constant observed phase for each pixel during the entire slave images stack, the phases are chosen randomly for each scatterer and maintained the same value for the entire slave images stack, and in order to simulate the effect of soil liquefaction, we add a random phase component, based on uniform distribution, to the chosen slave phase of every scatterer to form the master image phase eq. (1.d) (Fig. 3.b). We also add a circular Gaussian phase noise to the real and imaginary components of the complex observation with gradually incremented standard deviation, $\sigma_{\mathrm{n}}$, from 0.05 to 0.8 (rad.).

$\gamma_{c}=\frac{\left|E\left[s_{1} \cdot s_{2}^{*}\right]\right|}{\sqrt{E\left[\left|s_{1}\right|^{2}\right] \cdot E\left[\left|s_{2}\right|^{2}\right]}}$

$\gamma_{t}=\left|\frac{1}{N_{S}} \sum_{i=1}^{N_{S}} e^{j \Phi_{\text {simulated InSAR }}^{i}}\right|$

$\mathrm{S}_{\text {Slave,pixel }}=1 \cdot \mathrm{e}^{\mathrm{j}\left(\varphi_{\text {slave }}^{\text {scatterer }}\right)}+\sum_{i=1}^{5}\left(0.1 \cdot \mathrm{e}^{\mathrm{j}\left(\varphi_{\text {slave }}^{\text {scatterer }}\right)}\right)_{i}+$ Noise 
$\mathrm{S}_{\text {Master,pixel }}=1 \cdot \mathrm{e}^{\mathrm{j}\left(\varphi_{\text {slave }}^{\text {Scatterer }}+\text { rand } \cdot 2 \pi\right)}+\sum_{i=1}^{5}\left(0.1 \cdot \mathrm{e}^{\mathrm{j}\left(\varphi_{\text {slave }}^{\text {scatterer }}+\text { rand } \cdot 2 \pi\right)}\right)_{i}+$ Noise

where $s_{1}$ and $s_{2}$ are the master and slave complex phase, $\mathrm{j}=\sqrt{-1}, N_{s}$ is the number of simulated interferometric phase, in this analysis equals 30 , and $\varphi_{\text {slave }}^{\text {scaterer }}=$ rand $\cdot 2 \pi$ which is applied only once for each scatterer in the slave images stack.

We generate 30 single-master interferograms using the simulated images. We use the 8-by-3 SLC patch of every interferogram to estimate its coherence eq. (1.a) and by averaging the coherence stack, we estimate the mean coherence value.As for the temporal correlation, it is estimated for each pixel in the patch eq. (1.b). We repeat this analysis 5000 times for each value of $\sigma_{\mathrm{n}}$ and calculate the corresponding coherence and temporal correlation mean values, the results are shown in (Fig. 4).

The results of this simulation demonstrate that, the temporal correlation of PS can be higher than 0.8 if the noise standard deviation is below 0.4 (rad.) (Fig. 4.a), even if the pixels were affected by random decorrelating deformation in a single event, conditioning that the postseismic image is used as a common master. On the other hand, the coherence mean values are very low. It is noticed that the mean coherence value in the simulation analysis is constant and have a non-zero value, regardless of the simulation assumption of total loss of spatial phase coherence. This result is attributed to the fact that the estimation of spatial coherence using eq. (1.a) is biased, and it requires using many pixels to avoid coherence overestimation, (multi-look interferograms). In this study, we aim at fine spatial classification of PS pixels; therefore, we use a small window to estimate coherence to be consistent with the target of the proposed methodology, therefore, this constant value is equivalent to the total coherence loss. A scatter plot between the temporal correlation and coherence is presented in (Fig. 4.b), it is clear that the coherence values are following Gaussian distribution centered on the 0.2 value, this is mainly because the random phase noise that were added to the simulated observed phase were chosen based on Gaussian distribution. For PS analysis in area that contains liquefied and non-liquefied regions, and after selecting PS pixels using temporal phase stability analysis, a coherence threshold of 0.6 for the mean coherence map can be used to identify PSs in non-liquefied regions (Fig. 4.b).

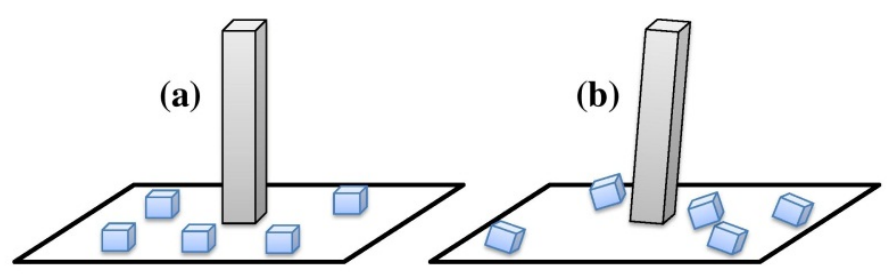

Fig.3. (a) Pixel contains a PS before soil liquefaction, and (b) after soil liquefaction. 

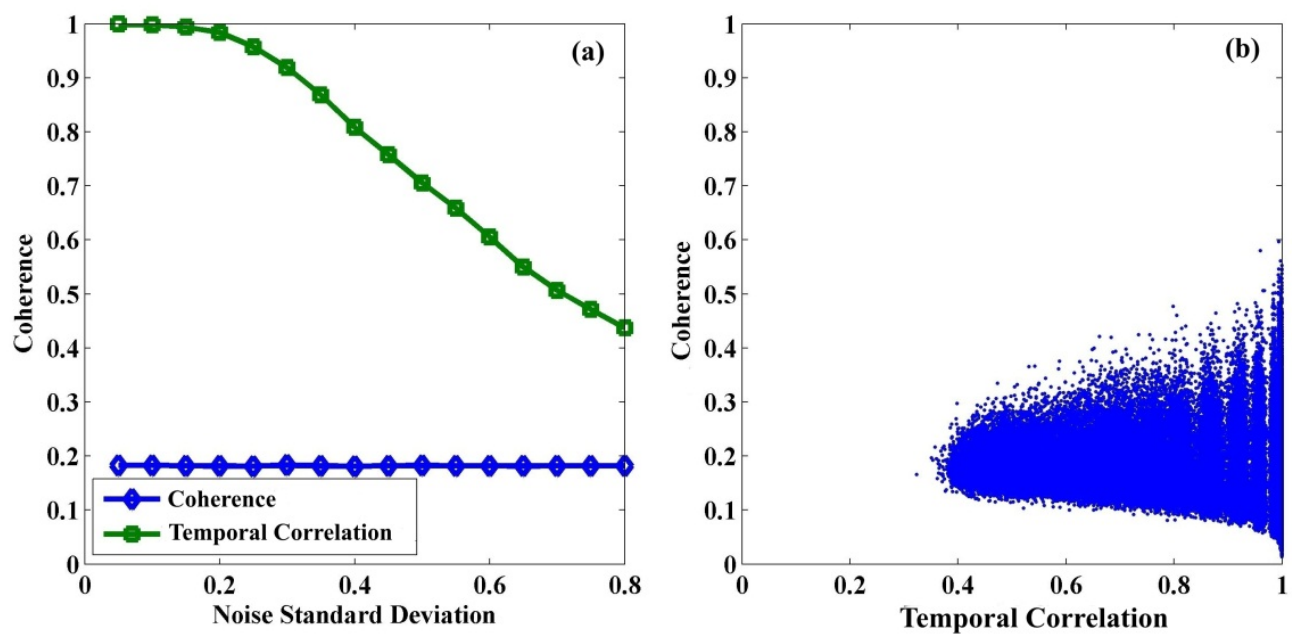

Fig.4. Numerical simulation results for PS in liquified reagions, (a) mean coherence and temporal correlation versus noise standard deviation, the analysis was repeated 5000 times for each value of $\boldsymbol{\sigma}_{\mathbf{n}}$, (b) scatter plot between coherence and temporal correlation.

\section{Methodology}

\subsection{InSAR Analysis}

In this analysis, we start by generating a stack of single-master-single-look interferograms. Assume the number of available SAR images and generated interferograms to be $N+1$ and $N$, respectively. We use a postseismic image as a common master and a stack of preseismic images as slaves. In this interferometric stack the main coseismic shock of the earthquake is presented in every interferogram, therefore, the near linear velocity requirement for PS analysis is preserved. After interferograms generation, a spatial filtering is applied to enhance the signal-to-noise ratio, SNR, of the interferometric phase (Perissin and Wang, 2012).

The interferometric phase generated using two single look complex (SLC) images is presented in eq. (2). Where $W\{\cdot\}$ is the wrapping operator and $\phi_{\text {Topo }}^{\text {Res }}$ is the residual topographic component after removing the topography effects using Digital Elevation Model (DEM). In this research, we use the Shuttle Radar Topography Mission (SRTM-3) DEM to remove the topography effects presented in interferograms. The interferometric phase also contains deformation effects $\phi_{\text {Deform }}$, atmospheric delay effects $\phi_{\text {Atm }}$, baseline error effects $\phi_{\text {Baseline }}$ and noise effects $\phi_{\text {Noise }}$. In this analysis, the deformation component, in any interferogram, can be further decomposed to the preseismic mean velocity component $\phi_{\text {Mean Velocity }}$, the earthquake main coseismic shock component $\phi_{E Q \text { shock }}$ and the liquefaction component $\phi_{\text {Liquefaction }}$ eq. (3).

$\Phi_{\text {InSAR }}=W\left\{\phi_{\text {Topo }}^{\text {Res }}+\phi_{\text {Deform }}+\phi_{\text {Atm }}+\phi_{\text {Baseline }}+\phi_{\text {Noise }}\right\}$

$\phi_{\text {Deform }}=\phi_{\text {Mean Velocity }}+\phi_{E Q \text { shock }}+\phi_{\text {Liquefaction }}$

Our main target is estimating the deformation due to liquefaction $\phi_{\text {Liquefaction }}$, which is only presented in the master image and expected to have very short correlation distance that can be assumed as spatially uncorrelated. On the other hand, the other components are either spatially correlated $\left(\phi_{\text {Atm }}, \phi_{\text {Baseline }}, \phi_{E Q}\right.$ shock $)$, or can be estimated using a periodogram $\left(\phi_{\text {Mean Velocity }}, \phi_{\text {Topo }}^{\text {Res }}\right)$. Based on these observations, the analysis strategy is constructed. First, limiting the analysis to those pixels that are most likely contain a PS, this will increase the SNR and the reliability of the observed phase. Second, estimating and removing the mean velocity, $\phi_{\text {Mean Velocity }}$, and DEM error, $\phi_{\text {Topo }}^{\text {Res }}$, from the observed phase. Third, identifying the master image contribution, and fourth, removing the spatially correlated phase to isolate the liquefaction deformation effect,

$\phi_{\text {Liquefaction }}$. 


\subsection{Identify PS Pixels}

To identify pixels that contain PSs, we use the method proposed by Hooper et al. (2007). Initially, a subset of pixels were selected based on their amplitude dispersion index, $D_{\mathcal{A}}$, which is defined by Ferretti et al. (2001) as eq. (4), where $\sigma_{\mathcal{A}}$ and $\mu_{\mathcal{A}}$ are the standard deviation and the mean of a series of amplitude values, respectively.

$D_{\mathcal{A}} \cong \frac{\sigma_{\mathcal{A}}}{\mu_{\mathcal{A}}}$

For pixels that contain a PS, the noise effect, $\phi_{\text {Noise }}$, is small enough not to obscure the signal, more precise identification for those pixels can be done by estimating the phase stability for each pixel using phase analysis. Recalling eq. (2), the contribution of the first four terms dominates the noise term, making it difficult to identify PS pixels. Therefore, in order to get an estimate for the noise term $\phi_{\text {Noise }}$, these four terms should be estimated and removed from the interferometric phase $\Phi_{I n S A R}$. The first four terms in eq. (2) are spatially correlated, except for the liquefaction effect $\phi_{\text {Liquefaction }}$ and the DEM error $\phi_{\text {Topo }}^{\text {Res }}$ which tends to be partly spatially correlated.

To estimate the spatially correlated component of the phase, Hooper et al. (2007) proposed to apply a band-passfilter that adapts to any phase gradient present in the data. They implemented a band-pass filter as an adaptive phase filter combined with a low-pass filter, applied in the frequency domain. A comprehensive description for approach proposed by Hooper et al. (2007) is given for completeness.

First, each pixel is weighted by setting the amplitude in all interferograms to an estimate of the SNR for the pixel, which in the first iteration it is set as $1 / D_{\mathcal{A}}$. Second, the complex phase of the weighted PS pixels is sampled to a grid with spacing of $100 \mathrm{~m}$ to enable using 2-D fast Fourier transform. Third, 2-D FFT is applied to a grid size of 32-by-32 cells and the intensity is smoothed by convolution with a 7-by-7 pixel Gaussian window eq. (5). Fourth, the adaptive phase filter response, $\mathrm{H}(u, v)$, is combined with a narrow low-pass filter response, $\mathrm{L}(u, v)$, to form the new filter response, $G(u, v)$ eq. (6), and by applying the new filter to the resampled observed phase in frequency domain, FFT $\left[\Phi_{\text {InSAR }}\right]$, the spatially correlated phase component, $\bar{\Phi}_{\text {InSAR }}$, will be obtained after 2D inverse FFT eq. (7), where $\mathrm{L}(u, v)$ is the fifth-order Butterworth filter, with a typical cutoff wavelength of $800 \mathrm{~m}$, and $\overline{\mathrm{H}}(u, v)$ is the median value of $\mathrm{H}(u, v)$.

$$
\begin{aligned}
& \mathrm{H}(u, v)=\left|\operatorname{Gaussian}(u, v) * F F T\left[\Phi_{\text {InSAR }}\right]\right| \\
& \mathrm{G}(u, v)=\mathrm{L}(u, v)+0.3\left(\frac{\mathrm{H}(u, v)}{\overline{\mathrm{H}(u, v)}}-1\right) \\
& \bar{\Phi}_{\text {InSAR }}=\operatorname{IFFT}\left[\mathrm{G}(u, v) * F F T\left[\Phi_{\text {InSAR }}\right]\right]
\end{aligned}
$$

Fifth, subtracting the filtered phase, $\bar{\Phi}_{\text {InSAR }}$, from the observed phase, $\Phi_{\text {InSAR }}$, and rewrapping. This will give an estimation of the spatially uncorrelated phase eq. (8). The first term in the right hand side of eq. (8) is expected to be small, therefore we will replace this term by $\delta$. As for the second term, the combined effects of the spatially uncorrelated component of the DEM error, $\phi_{\text {Topo }}^{\text {Res.u }}$, and the PS slant range location within the pixel (Ferretti et al., 2001) can be estimated as an error in the look angle, $\theta^{u},\left[\phi_{\theta}^{u}=\frac{4 \pi}{\lambda} B_{\perp} \cdot \theta^{u}\right]$, using a periodogram eq. (9) where, $B_{\perp}$ is the perpendicular baseline and $\lambda$ is the signal wavelength. Meanwhile, the effect of liquefaction, $\phi_{\text {Liquefaction }}$, can be considered as a constant bias.

$$
\begin{aligned}
& W\left\{\Phi_{\text {InSAR }}-\bar{\Phi}_{\text {InSAR }}\right\}=W\left\{\phi_{\text {Mean Velocity }}^{u}+\phi_{\text {EQ shock }}^{u}+\phi_{\text {Atm }}^{u}+\phi_{\text {Baseline }}^{u}\right\}+W\left\{\phi_{\text {Topo }}^{\text {Res.u }}+\right. \\
& \left.\phi_{\text {Liquefaction }}+\phi_{\text {Noise }}\right\} \\
& \arg \max _{\widehat{\theta}^{u}}\left\{\gamma_{x}=\left|\frac{1}{N} \sum_{i=1}^{N} e^{j\left(\Phi_{\text {InSAR }}-\bar{\Phi}_{\text {InSAR }}\right)} \cdot e^{-j\left(\frac{4 \pi}{\lambda} B_{\perp i} \cdot \widehat{\theta}^{u}\right)}\right|\right\}
\end{aligned}
$$


Sixth, subtracting the estimated phase due to look angle error, $\hat{\phi}_{\theta}^{u}$, from eq. (8), and assuming that $\delta \approx 0$, makes eq. (10) the first estimation of the noise component $\hat{\phi}_{\text {Noise }}$.

$W\left\{\Phi_{\text {InSAR }}-\bar{\Phi}_{\text {InSAR }}-\hat{\phi}_{\theta}^{u}\right\}=W\left\{\delta+\hat{\phi}_{\text {Noise }}\right\}$

Seventh, using the estimated noise phase $\widehat{\phi}_{\text {Noise }}$ to calculate the SNR for every pixel using eq. (11), where $g$ is the signal amplitude which assumed to be constant, $A$ is the observed amplitude and $\hat{\sigma}_{n}^{2}$ is the noise variance. Finally, to get a better estimate for the noise phase, the process is repeated using the estimated SNR as a weight factor. The system converges when the difference of $\gamma_{x}$ between iterations cease of decreasing. In this analysis, we select PS pixels by setting a threshold to the final estimation of $\gamma_{x}$.

$S N R=\frac{g^{2}}{2 \sigma_{n}^{2}}$

$\hat{g}=\frac{1}{N} \sum_{i=1}^{N} A_{i} \cos \hat{\phi}_{\text {Noise }, i}$

$\hat{\sigma}_{n}^{2}=\frac{1}{2}\left[\frac{\sum_{i=1}^{N} A_{i}^{2}}{N}-\hat{g}^{2}\right]$

\subsection{PS Analysis}

In this analysis, we use the phase difference between neighboring pixels as the basic observation. This should reduce the effect of spatially correlated errors during the process of estimating the mean velocity and DEM error for PS pixels. This technique was proved to be efficient by several researchers e.g., (Ferretti et al., 2000; Mora et al., 2003; Liu et al., 2009; Zhang et al., 2014)

After identifying the PS pixels, a network is constructed to connect PS pairs; each connection is called an arc. For that purpose, we use Delaunay triangulation network to connect all PSs in an interferogram. A maximum arc length of $800 \mathrm{~m}$ is set to reduce the effect of atmospheric component (Williams et al., 1998). Assume the number of arcs to be $M$ and the number of PS pixels to be $K$.

The phase difference between two PSs, $[a, b]$, in the $i^{\text {th }}$ interferogram can be expressed as in eq. (12).

$$
\begin{aligned}
& \Delta \Phi_{a, b}^{i}=W\left\{\Delta \phi_{\text {Topos, } a, b}^{\text {Res }}+\Delta \phi_{\text {Mean Velocity,a,b }}^{i}+\Delta \phi_{E Q \text { shock }, a, b}^{i}+\Delta \phi_{\text {Liquefaction }, a, b}^{i}+\Delta \phi_{\text {Atm }, a, b}^{i}+\right. \\
& \left.\Delta \phi_{\text {Baseline }, a, b}^{i}+\Delta \phi_{\text {Noise }, a, b}^{i}\right\}, \quad i=1: N
\end{aligned}
$$

For neighboring pixels with distance less than $800 \mathrm{~m}$, the spatially correlated errors, $\left(\Delta \phi_{A t m, a, b}^{i}, \Delta \phi_{\text {Baseline, } a, b}^{i}\right)$, are significantly reduced. As for the master effect, $\left(\Delta \phi_{E Q}^{i}\right.$ shock,a,b,$\left.\Delta \phi_{\text {Liquefaction }, a, b}^{i}\right)$, it is represented in every interforgram and can be treated as a constant bias. Therefore, eq. (12) can be rewritten as eq. (13)

$\Delta \Phi_{a, b}^{i}=W\left\{\frac{4 \pi}{\lambda} \frac{B_{\perp i}}{r_{i} \cdot \sin \vartheta_{i}} \Delta h_{a, b}+\frac{4 \pi}{\lambda} t_{i} \Delta v_{a, b}+\Delta w_{a, b}^{i}\right\}, \quad i=1: N$

where, $\Delta \Phi_{a, b}^{i}$ is the differential phase observation between pixels $a$ and $b$ in the $i^{\text {th }}$ interferogram, $\Delta v_{a, b}$ and $\Delta h_{a, b}$ are the mean velocity difference and DEM error difference for the arc, respectively, $t_{i}$ is the time difference between the master and slave images that form the interferogram, $\lambda$ is the signal wavelength, $\Delta w_{a, b}^{i}$ is the residual component for the arc in the $i^{\text {th }}$ interferogram, $B_{\perp i}, r_{i}$ and $\vartheta_{i}$ are the perpendicular baseline, the sensor target distance and the incident angle, respectively.

To estimate the mean velocity difference, $\Delta v_{a, b}$, and DEM error difference, $\Delta h_{a, b}$, for an arc, we use the periodogram presented in eq. (14)

$\arg \max _{\Delta h_{a, b}, \Delta v_{a, b}}\left\{\gamma=\left|\frac{1}{N} \sum_{i=1}^{N} e^{j\left(\Delta \Phi_{a, b}^{i}\right)} \cdot e^{-j\left(\frac{4 \pi}{\lambda} \frac{B_{\perp i}}{r_{i} \cdot \sin \vartheta_{i}} \Delta h_{a, b}+\frac{4 \pi}{\lambda} t_{i} \Delta v_{a, b}\right)}\right|\right\}$ 
After estimating the mean velocity difference, $\Delta v$, and the DEM error difference, $\Delta h$, for the whole arcs network, the residual component for the arcs network in every interferogram , $\Delta w^{i}$, can be estimated. After discarding arcs with $\gamma$ below a preset threshold, the mean velocity and DEM error for each pixel, with respect to an arbitrary reference PS pixel, can be estimated using least squares inversion. eq. (15)

$\boldsymbol{L}=\boldsymbol{A} \cdot \boldsymbol{P}$

with

$\boldsymbol{A}=\left[\begin{array}{ccc}1 & 0 & \cdots \\ 1 & -1 & \cdots \\ \vdots & \vdots & \ddots\end{array}\right]_{M \times K}, \boldsymbol{L}=\left[\begin{array}{c}\Delta v_{1} \\ \vdots \\ \Delta v_{M}\end{array}\right]$ and $\boldsymbol{P}=\left[\begin{array}{c}v_{1} \\ \vdots \\ v_{K}\end{array}\right]$

Where, $\boldsymbol{A}$ is the design matrix relating the arcs, $M$, with the PS pixels $K, \boldsymbol{L}$ contains the estimated mean velocity difference for the arcs and $\boldsymbol{P}$ is the unknown mean velocity vector for the PS pixels. The DEM error can be estimated using the same approach.

It should be noted that eq. (15) is a large sparse linear system and it can be resolved by an iterative method based on bidiagonalization procedure that appears in Matlab as a built-in LSQR function (Paige and Saunders, 1982).

\subsection{Estimating Liquefaction Effect}

The liquefaction effect is part of the master image contribution to the residual phase, $\Delta w^{i}$. In single master interferometric stack, the master image contribution, for an arc $\Delta w_{k}^{\text {Master }}$, can be estimated by calculating the mean value of residual stack of that arc eq. (16). Then, the master residual phase component of each PS pixel can be estimated using least squares inversion. eq. (15)

$\Delta w_{k}^{\text {Master }}=\frac{1}{N} \sum_{i=1}^{N} \Delta w_{k}^{i}, k=1: M$

The residual phase component of the PS pixels in master image, $W\left\{w^{\text {Master }}\right\}$, is identified using the same approach as eq. (15). As a result of using least squares inversion, the extracted phase is expected to be partially unwrapped. To avoid the errors in this rough phase unwrapping process, such as phase aliasing, we rewrap the extracted phase and use Delaunay Minimum Cost Flow (DMCF) (Costantini and Rosen, 1999) for phase unwrapping instead. The result of this process is the unwrapped residual phase of the master image, $w^{\text {Master }}$.

In our study area, the identified PS pixels can be categorized into two groups, PS pixels located in liquefied regions and PS pixels located in non-liquefied regions. The residual master phase of the first group, liquefied pixels $w_{\text {Liq }}^{\text {Master }}$, is presented in eq. (17), which contains the liquefaction effect, $\phi_{\text {Liquefaction }}$, and the spatially correlated components, $\left(\phi_{E Q \text { shock }}, \phi_{A t m}, \phi_{\text {Baseline }}\right)$. As for the second group, non-liquefied pixels, the residual master phase, $w_{\text {NonLiq }}^{\text {Master }}$, is presented in eq. (18), those pixels contain only the spatially correlated components.

$$
\begin{aligned}
& w_{\text {Liq }}^{\text {Master }}=\phi_{E Q \text { shock }}+\phi_{\text {Liquefaction }}+\phi_{\text {Atm }}+\phi_{\text {Baseline }} \\
& w_{\text {NonLiq }}^{\text {Master }}=\phi_{E Q \text { shock }}+\phi_{\text {Atm }}+\phi_{\text {Baseline }}
\end{aligned}
$$

The spatially correlated components can be removed using spatial phase filtering; this process should isolate the liquefaction deformation component. To avoid contaminating the liquefaction component during the spatial phase filtering, we use only the PS pixels that are most likely in non-liquefied regions.

In order to identify PS pixels in non-liquefied regions, we set a threshold to the mean coherence map, which is the mean of the coherence of all interferograms. To avoid coherence overestimation, we calculate the coherence using a 9-by-3 pixels window, in azimuth and range directions, respectively. The window is centered over each PS pixel, and the estimated coherence value is assigned to that PS pixel. This coherence estimation reflects the stability of the PS surrounding pixels. Finally, we can identify the PS pixels in non-liquefied areas by using a coherence threshold of $>0.6$, based on the simulation analysis in section 2.3 . 
The residual phases of PS pixels located in non-liquefied areas are expected to contain only the spatially correlated component eq. (18), therefore, we use those pixels to estimate and remove the low-pass component of the phase. First, we interpolate phase values to a regular grid using cubic 2-D interpolation. Second, we smooth the interpolated phase by 2-D Gaussian filter, and finally, we subtract the smoothed phase from the master image residual phase, $w^{\text {Master }}$. The resulting phase is expected to contain the coseisimc spatially uncorrelated deformation, i.e. deformations due to soil liquefaction.

\section{Testing with Synthetic Data}

To assess the performance of the analysis method, a test with synthetic data is conducted first. Using synthetic data allows a quantitative analysis of the proposed method's accuracy. In this test, we simulate the phase of 2000 PS pixels in 31 SLC images with time interval of 30 days and dimensions of $5 \mathrm{~km} \times 4 \mathrm{~km}$ in the range and azimuth directions, respectively, using ALOS-PALSAR parameters. The simulated phases include linear deformation rate, topography error, atmospheric delay, baseline error, noise and the expected earthquake effects.

The linear deformation rate is simulated as a bowl with maximum velocity of $5 \mathrm{~cm} /$ year (Fig. 5.a). The simulated topography error has a uniform distribution between $-10 \mathrm{~m}$ and $10 \mathrm{~m}$ (Fig. 5.b). Atmospheric delay, baseline error and noise are simulated for each SLC image. The atmospheric signal is simulated using fractal surfaces with dimension of 2.67 (Hanssen, 2001), the maximum variation of the simulated atmospheric delay is about 2.5 rad (Fig. 5.e). The baseline error is simulated as 2-D surface, and the maximum and minimum values are assigned randomly for each image between the values -9 and 9 rad (Fig. 5.f). The noise effect is randomly set to a mean of $20^{\circ}$ with standard deviation of $10^{\circ}$ (Fig. 5.g). The earthquake coseismic shock is simulated as 2-D surface ranging from $-20 \mathrm{rad}$ to $-30 \mathrm{rad}$ (Fig. 5.c), and the liquefaction effect is simulated as local deformation with different patterns ranging from $-6 \mathrm{~cm}$ to $7 \mathrm{~cm}$ (Fig. 5.d), these contributions are added to the master image only (Fig. 5.h). The simulated phases sample presented in (Fig. 5) is used to form the master SLC image.

In this test, a total number of 30 interferograms, with perpendicular baseline ranging from $-2 \mathrm{~km}$ to $2 \mathrm{~km}$ and temporal baseline up to 900 days, are generated using 31 simulated SLC images (Fig. 6). We start the analysis by estimating the interferometric phase for the 2000 PS pixels which are randomly distributed over the study area. Then, we construct Delaunay triangulation network to connect the pixels, a total of 11652 arcs were generated. Using periodogram, we estimate the relative mean velocity, DEM error and residual component for each arc. After discarding the arcs that give temporal coherence, $\gamma$, less than 0.8 eq. (14) and removing the isolated PS pixels, we use eq. (15) to estimate the mean velocity and DEM error for the 1963 remaining pixels.

To estimate the liquefaction effect, first, we use eq. (16) to identify the contribution of master image and eq. (15) to estimate the residual phase component of every PS pixel. Then we remove the pixels located in liquefied regions, simulating the process of the spatial coherence threshold. Finally, we use only $30 \%$ of the remaining pixels in spatial phase filtering.

It is noticed that, when the spatially correlated error, such as baseline error, are significantly large, it may affect the estimated mean velocity and DEM error by an imposed phase gradient. To avoid this effect, an estimation of the phase gradient using a periodogram can be added to the analysis. Considering the fact that in this analysis we are not interested in the spatially correlated component of the phase, applying a simple ramp removal to the estimated mean velocity and DEM error would be sufficient.

The estimated linear velocity, DEM error, liquefaction effect and the associated estimation error are presented in Fig. 7. Also, a statistical analysis of the estimation error is given in (Table 1), showing RMSE of the estimated linear velocity, DEM error and liquefaction effect of $1.68 \mathrm{~mm} /$ year, $0.73 \mathrm{~m}$ and $5.23 \mathrm{~mm}$, respectively. 


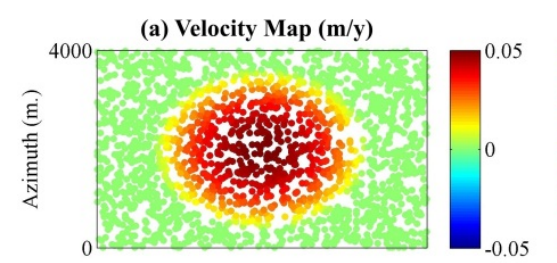

(b) DEM Error (m.)
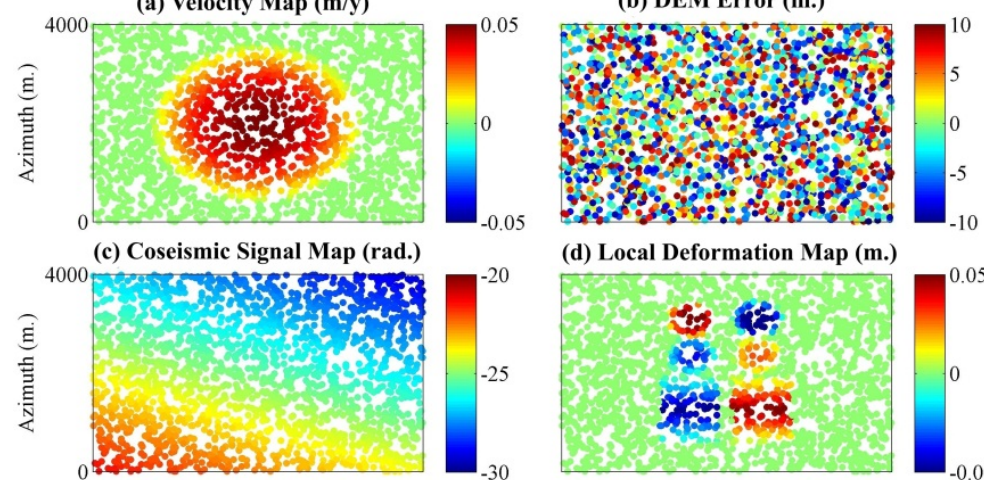

(d) Local Deformation Map (m.)
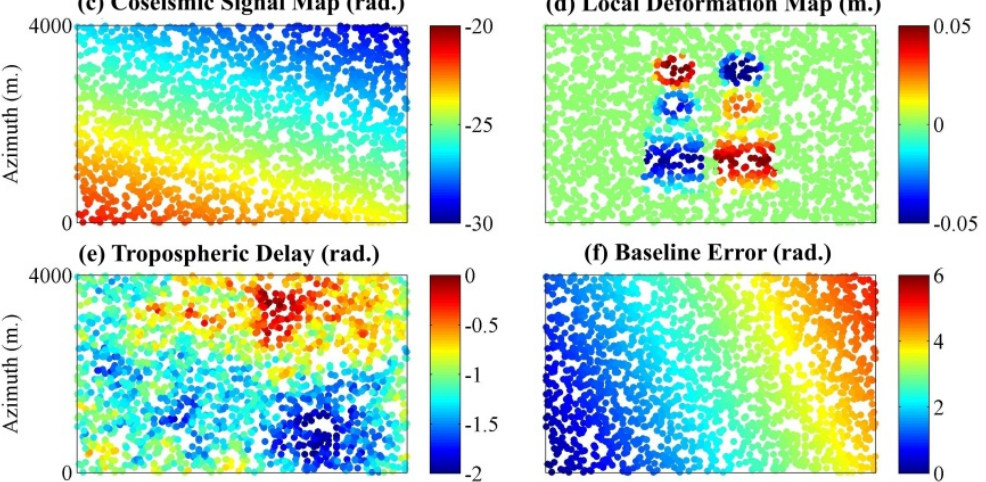

(f) Baseline Error (rad.)
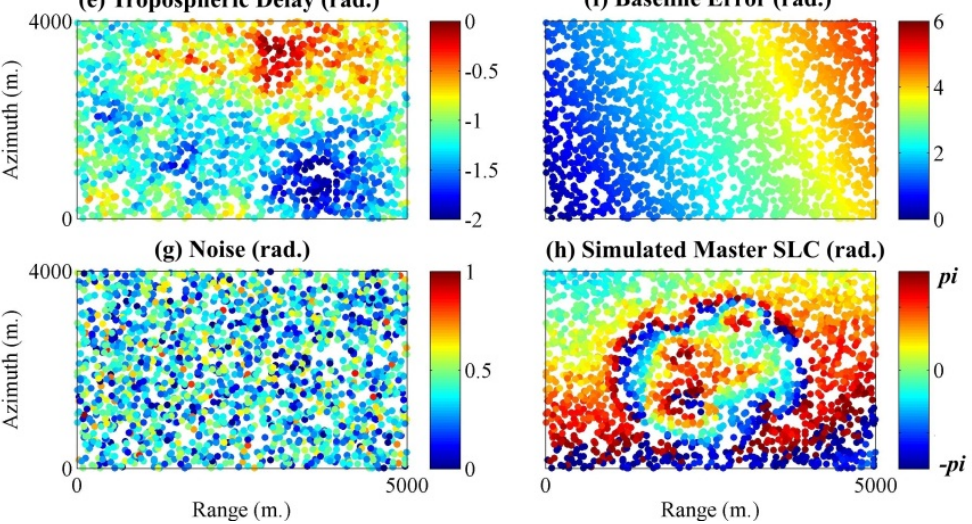

Fig.5. Sample of the simulated phases,(a) Linear deformation rate, (b) DEM error, (c) Main coseismic shock of the earthquake "in master image only", (d) Local deformation simulating liquefaction effect "in master image only”, (e) Tropospheric delay effect, (f) Baseline error, (g) Simulated noise, (h) The simulated master SLC.
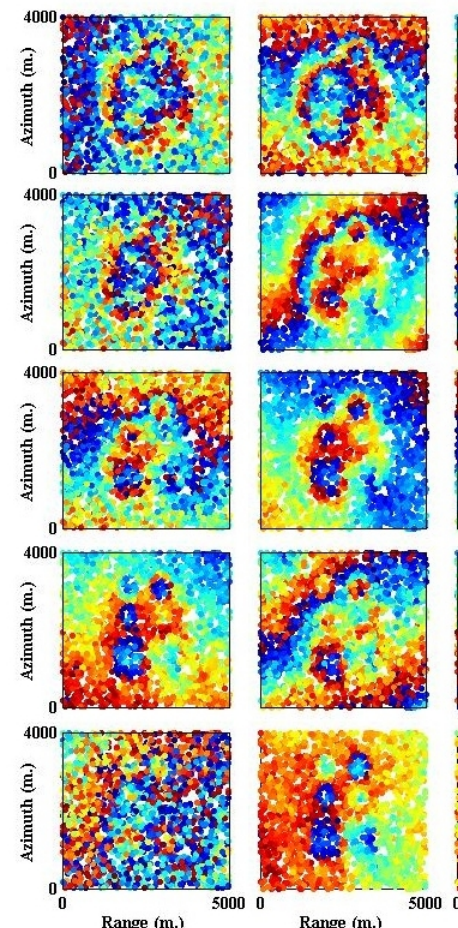
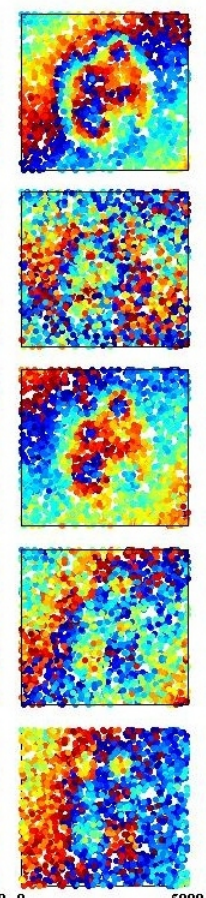

Range (m.)
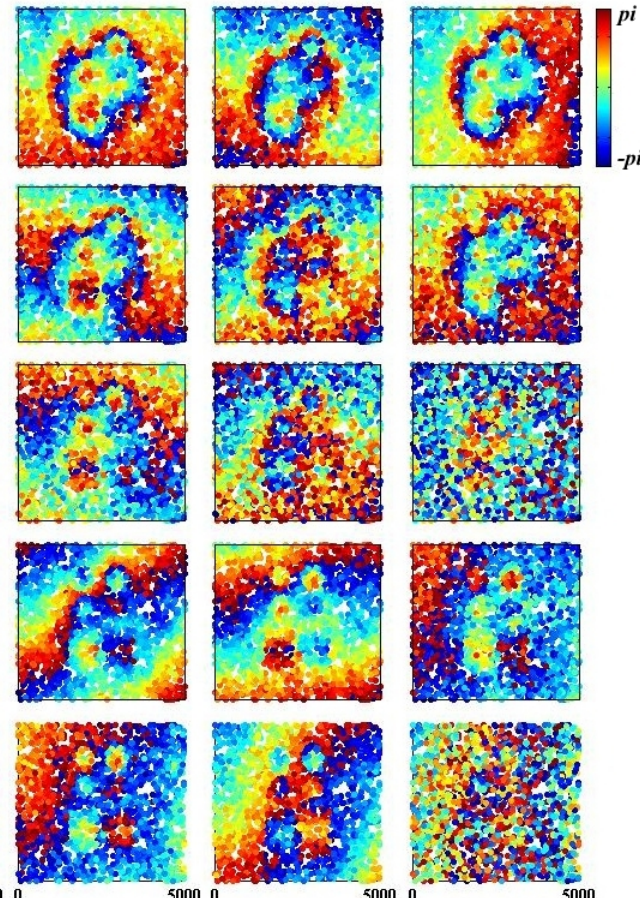

Range (m.)
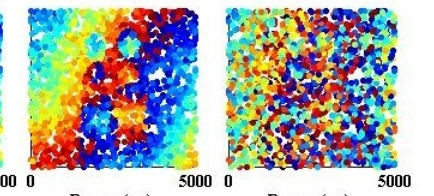

Fig.6. Generated interferograms using the simulated SLC images. 
(a) Estimated Velocity Map (m/y)

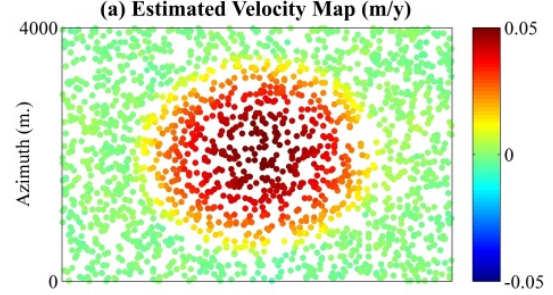

(c) Estimated DEM Error (m.)

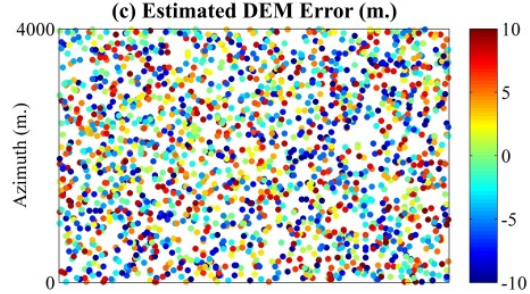

(e) Estimated Local Deformation (m.)

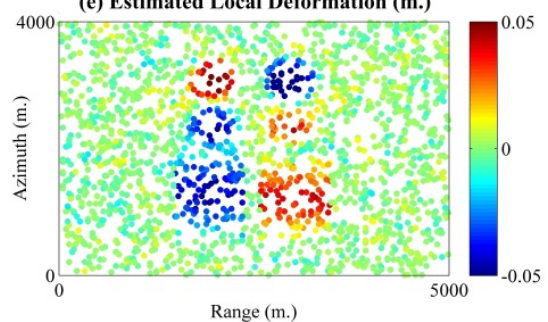

(b) Estimated Velocity Error (m/y)

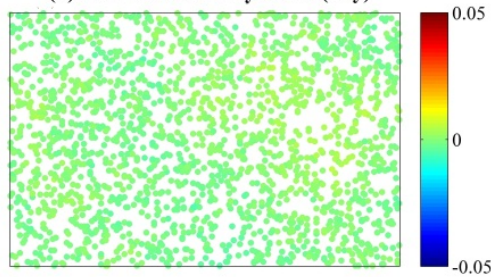

(d) Error in Estimated DEM Error (m.)

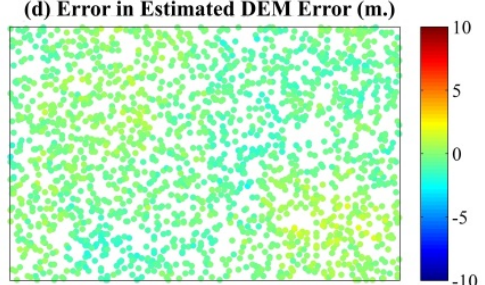

(f) Local Deformation Error (m.)

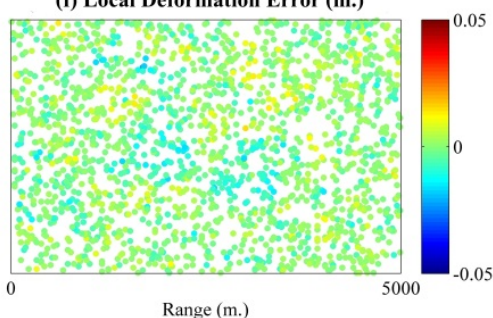

Fig.7. (a) Estimated linear deformation rate, (b) Error in the estimated linear deformation rate, (c) Estimated DEM error, (d) Error in the estimated DEM error, (e) Estimated local deformation, (f) Error in the estimated local deformation.

Table 1

Statistical analysis results for the simulation test

\begin{tabular}{|l|c|c|c|}
\hline & Mean & $\begin{array}{c}\text { Standard } \\
\text { Deviation }\end{array}$ & RMSE \\
\hline Error in the estimated deformation rate $(\mathrm{mm} /$ year) & -0.26 & 1.66 & 1.68 \\
\hline Error in the estimated DEM error & -0.35 & 0.64 & 0.73 \\
\hline Error in the estimated local deformation $(\mathrm{m})$ & -0.5 & 5.21 & 5.23 \\
\hline
\end{tabular}

\section{Estimating Liquefaction Deformation in Urayasu City}

\subsection{Data Preparation}

In this analysis we use 18 SAR images which were acquired by ALOS-PALSAR covering the period from 8 August 2006 to 6 April 2011. Data were provided by the Japan Aerospace Exploration Agency, JAXA. Single looked interferograms are generated using SARscape software as shown in (Table 2), the effect of topography is removed using SRTM-3 DEM, and Goldstein method (Goldstein and Werner, 1998) is used for filtering

\subsection{Analysis}

We start the analysis by calculating the dispersion index map using a series of ALOS-PALSAR amplitude images, and by setting a dispersion index threshold of, $D_{\mathcal{A}} \leq 0.5$, a first subset of 643,623 pixels are chosen. Then, the phase stability of each pixel is estimated using the procedure proposed by Hooper et al. (2007) and after setting a threshold of, $\gamma_{x} \geq 0.8$, only 192,062 pixels remain. The remaining pixels are connected using Delaunay triangulation network with maximum arc length of $800 \mathrm{~m}$. a total number of 1,150,956 arcs are generated. Next, we estimate the relative mean velocity and DEM error for each arc using eq. (14), and by setting an arc threshold of, $\gamma \geq 0.8$, and removing the isolated PS pixels, 190,329 pixels remain. The estimated mean velocity and DEM error for each pixel is calculated using eq. (15) and presented in (Fig. 8.a) and (Fig. 8.b), respectively. 
After estimating the residual component for each arc, the master image contribution is identified using eq. (16), eq. (15) and unwrapped using (DMCF) method. For phase filtering, we estimate the mean coherence map (Fig. 8.c) using the procedure described in section 3.4. We use a spatial coherence threshold of 0.8 , a total number of 21,838 pixels are identified and used for spatial phase filtering. The remaining deformation phase, which is believed to be due to soil liquefaction, are geocoded and presented in (Fig. 8.d).

Table 2

Details of SAR images and interferograms.

\begin{tabular}{|c|c|c|c|c|}
\hline Image & No. & $B \perp\left(m_{.}\right)$ & $\Delta \mathbf{t}$ (days) & $\begin{array}{l}\text { Satellite/Sensor } \\
\text { /Direction }\end{array}$ \\
\hline 2006-08-08 & 1 & -5066 & -1702 & \multirow{9}{*}{$\begin{array}{l}\text { ALOS - } \\
\text { PALSAR } \\
\text { L-band } \\
\text { Fine Beam Sin- } \\
\text { gle polarization } \\
\text { (FBS) (HH) }\end{array}$} \\
\hline 2006-09-23 & 2 & -4580 & -1656 & \\
\hline 2006-12-24 & 3 & -5470 & -1564 & \\
\hline 2007-05-11 & 4 & -3708 & -1426 & \\
\hline $2007-12-27$ & 5 & -3122 & -1196 & \\
\hline 2008-02-11 & 6 & -2494 & -1150 & \\
\hline 2008-03-28 & 7 & -1988 & -1104 & \\
\hline 2008-08-13 & 8 & -7004 & -966 & \\
\hline 2008-11-13 & 9 & -5712 & -874 & \\
\hline 2008-12-29 & 10 & -5964 & -828 & \multirow{9}{*}{$\begin{array}{c}\text { Ascending } \\
\text { Critical Normal } \\
\text { Baseline } \\
\text { (12500 m.) }\end{array}$} \\
\hline 2009-02-13 & 11 & -5100 & -782 & \\
\hline 2009-11-16 & 12 & -4219 & -506 & \\
\hline 2010-02-16 & 13 & -3530 & -414 & \\
\hline 2010-04-03 & 14 & -2792 & -368 & \\
\hline 2010-08-19 & 15 & -2332 & -230 & \\
\hline 2011-01-04 & 16 & -2194 & -92 & \\
\hline 2011-02-19 & 17 & -401 & -46 & \\
\hline 2011-04-06 & 18 & 0 & 0 & \\
\hline
\end{tabular}


(a) Estimated Velocity Map (m/y)

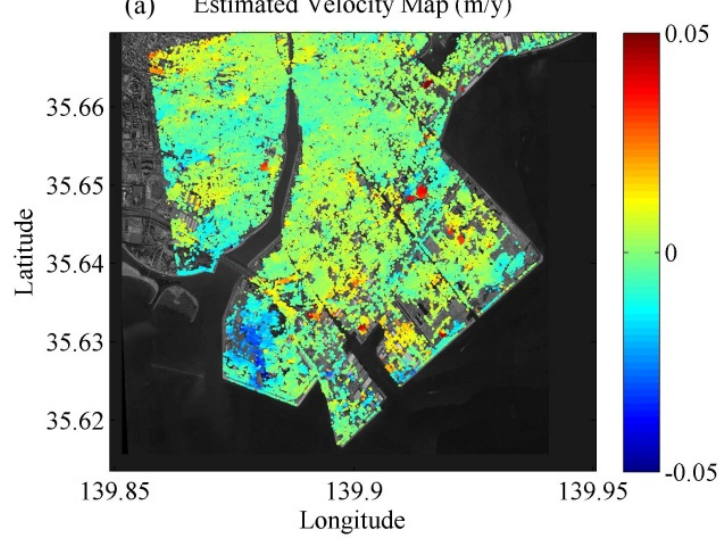

(c)

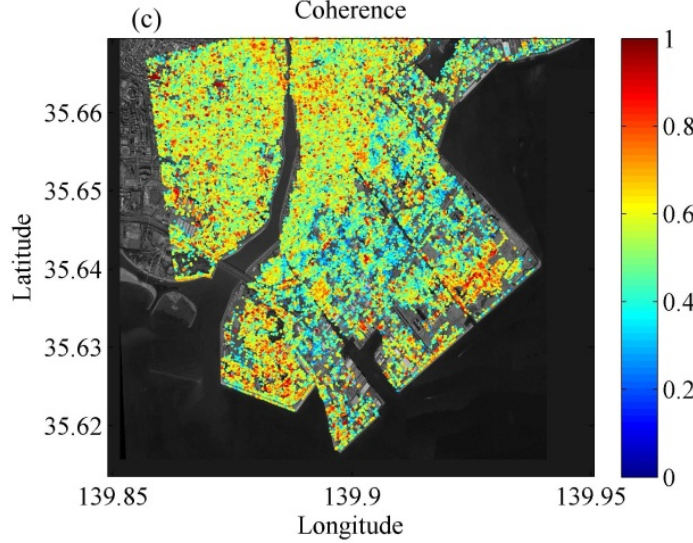

(b) Estimated DEM Error (m)

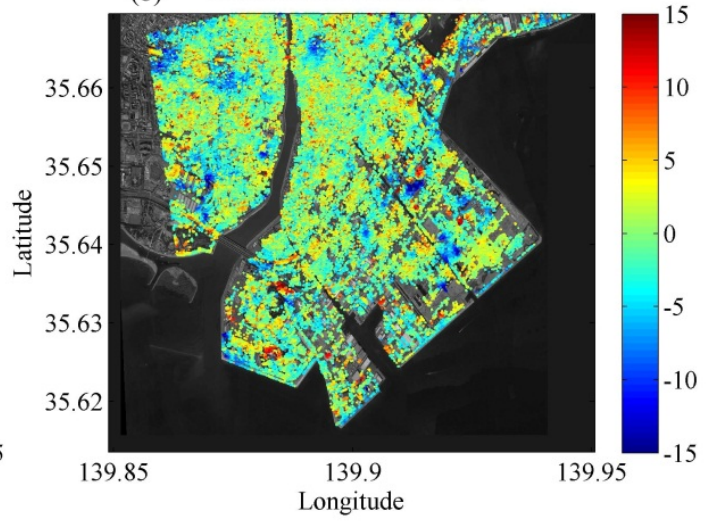

(d) Liquefaction Deformation (m)

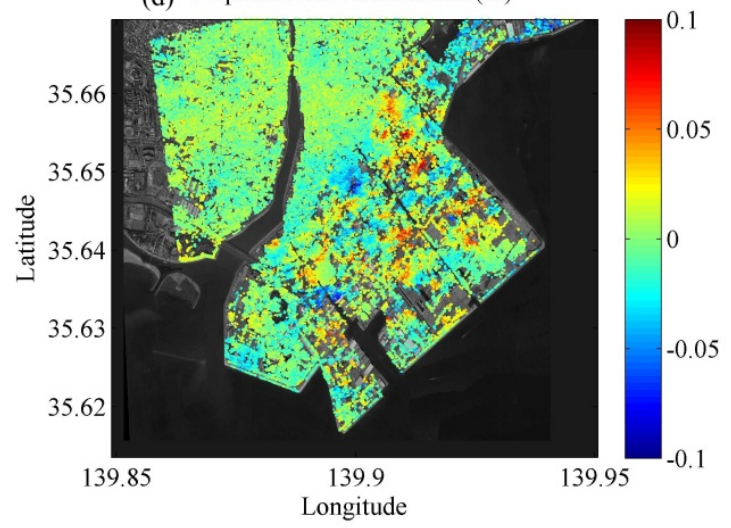

Fig.8. (a) Estimated mean velocity, (b) Estimated DEM error, (c) Mean coherence, (d) Liquefaction deformation. Data are overlayed on Google Earth image.

\subsection{Results}

In areas where liquefaction occurred, many sand boils, ground settlements as well as settlements and tilts of buildings and houses on spread foundation were observed. Vertical gaps were created around pile-supported structures due to ground settlements, causing damage to piping and other facilities (Tokimatsu et al., 2012). The effect of soil liquefaction on bare land and roads was severe, causing a total loss of signal coherence; therefore, the main idea of this research is detecting the deformation of the most stable scatterers that can provide a signal with minimum decorrelation, i.e. man-made structures.

Detecting the deformation of man-made structures (PSs) gives an estimation of the amount of tilt and subsidence of buildings, projected in the line-of-sight direction of the sensor. This estimation gives a clear indication of the damage severity of buildings, if exist. It is worth noting that, the full observation signature of the study area hardly showing any uplift or positive LOS values (ALOS-PALSAR, ascending direction) because of the 2011 Tohoku earthquake main coseismic shock effect. Nevertheless, after removing the spatially correlated component of the phase, the local deformation signature can have a positive or negative LOS values. A simple interpretation of the observed LOS deformation for PS pixels is given in (Fig. 9), where a positive LOS deformation value indicates tilting towards the sensor and negative LOS deformation value indicates tilting away from the sensor or vertical subsidence. 


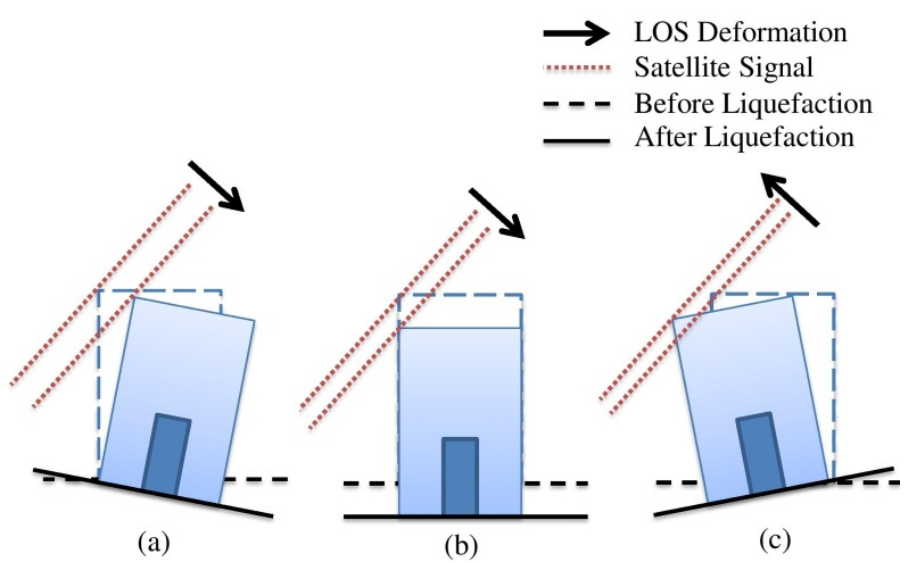

Fig.9. Signature of local deformation (a) Tilt away from sensor, negative value, (b) Vertical subsidence, negative value, (c) Tilt towards the sensor, positive value.

Because ground truth data of PS pixels deformation is not available, only a qualitative assessment can be conducted. Tokimatsu et al., (2012) created a damage map (Fig. 10.b) based on field performance of soils and buildings. They included ground settlements as well as the settlements and tilting of the houses. They classified the extent of soil liquefaction into four categories, namely, no liquefaction, slight liquefaction, moderate liquefaction and extensive liquefaction. In (Fig. 10.c), we present part of the soil liquefaction's damage map created by KRDB and JGS, which is demonstrated in (Fig. 2.c). The distribution of the average inclination angle of residential houses supported on spread foundations is presented in (Fig. 10.d) based on survey of about 9000 houses conducted by Urayasu city government and reported by (Tokimatsu and Katsumata, 2012). To facilitate the discussion of the results, we subdivide Urayasu city to several regions identified by letters, (Fig. 10.a) (Table 3), and, when needed, the region is further subdivided into districts identified by numbers.

Table 3

Regions of Urayasu city

\begin{tabular}{|c|c|c|c|}
\hline ID & Region & ID & Region \\
\hline A & Maihama & I & Irifune \\
\hline B & Higashina & J & Minato \\
\hline C & Kairaku & K & Takasu \\
\hline D & Benten & L & Akemi \\
\hline E & Tomioka & M & Hinode \\
\hline F & Mihama & N & Tokyo Disney Land \\
\hline G & Tekkodon & O & $\begin{array}{c}\text { Hilton and Sheraton Grande } \\
\text { Tokyo bay Hotels }\end{array}$ \\
\hline H & Imagawa & P & \\
\hline
\end{tabular}



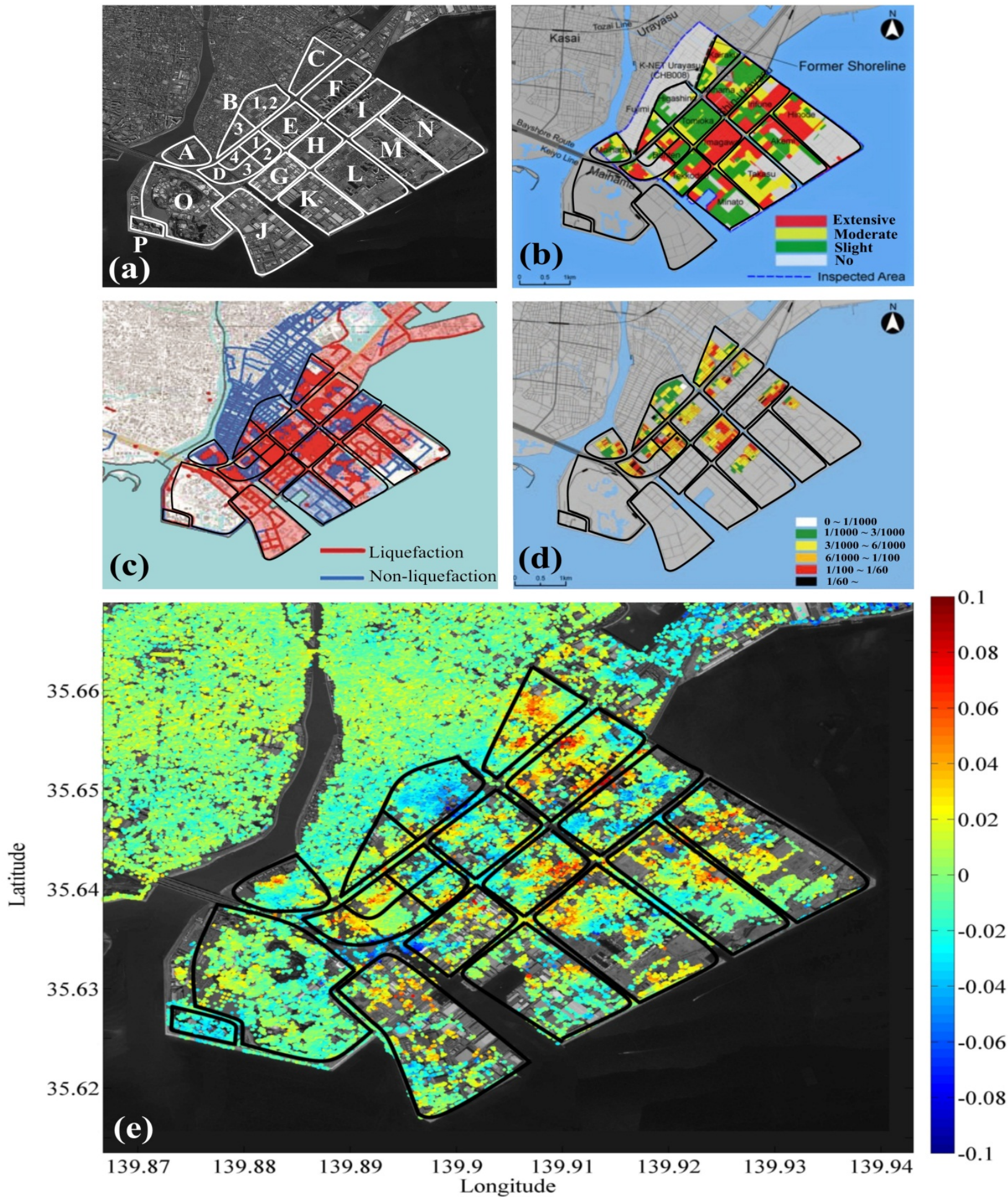

Fig.10. (a) Regions of Urayasu city (Table 3), (b) Soil liquefaction damage map (Tokimatsu et al., 2012), (c) Field survey for liquefaction areas conducted by KRDB and JGS (2011), (d) Average inclination angle map (Tokimatsu and Katsumata, 2012). (e) Soil liquefaction based on the proposed analysis, 


\section{Region B, Higashina.}

In Higahina region, districts no.1 \& 2, we detect a coseismic subsidence (Fig. 10.e), which was not reported by KRDB and JGS (Fig. 10.c) or Tokimatsu et al., (2012) (Fig. 10.b). A slight inclination angle of the buildings was detected by Urayasu city government (Fig. 10.d). This proves that, this region was subjected to a coseismic ground subsidence that did not damage the infrastructure but caused the buildings to subside and tilt.

In district no.3, we detect some deformation in the central part, which confirms the results of the field survey conducted by KRDB and JGS, Tokimatsu et al., (2012) and Urayasu city government. For the eastern and western parts the field surveys presented by KRDB and JGS and Tokimatsu et al., (2012) are contradicting to each other, therefore, the data of these parts are not dependable for results verification.

\section{Region D, Benten.}

In Benten region, districts no.1, 2 and 4, we detect variant deformation patterns that can be caused by soil liquefaction. In district no.3, the eastern part of the district shows no deformations, on the other hand, the western part shows large deformations (Fig. 10.e). These results confirm well with the field surveys conducted by KRDB and JGS (Fig. 10.c), Tokimatsu et al., (2012) (Fig. 10.b) and Urayasu city government (Fig. 10.d).

\section{Region K, Minato.}

In Minato region, we detect slight to no deformation signatures with the exception of the central part which shows large deformation (Fig. 10.e). These results confirm well with the field surveys conducted by Tokimatsu et al., (2012) (Fig. 10.b). The field survey conducted by KRDB and JGS (Fig. 10.c) (Fig. 2.c) for Minato region shows an assumed no-liquefaction classification, therefore, we discard this result in the verification.

\section{Region L, Takasu.}

In Takasu region, we detect some deformation in the central and western part that confirms with the field surveys. Nevertheless, in the below central region, we could not detect the deformation because it was bare land at the time of SAR acquisitions; therefore, no PS pixels are identified (Fig. 10.e).

\section{Regions M, Akemi and N, Hinode}

In Akemi and Hinode region, we detect deformations in the central and northern parts, but the eastern and southern parts shows no deformation signatures (Fig. 10.e). These results confirm well with the field surveys conducted by KRDB and JGS (Fig. 10.c) and Tokimatsu et al., (2012) (Fig. 10.b).

\section{Region O, Tokyo Disneyland}

In Tokyo Disneyland region, we did not detect any deformation signature (Fig. 10.e). This region was not included in the field surveys (Fig. 10.b), (Fig. 10.c) or (Fig. 10.d).

\section{Region P, Hilton and Sheraton Grande Tokyo bay Hotels}

We detect uniform deformations in the region of the Hilton and Sheraton Grande Tokyo bay Hotels (Fig. 10.e). The detected deformation ranges from $-2 \mathrm{~cm}$ to $-4 \mathrm{~cm}$ and indicates the occurrence of coseismic ground subsidence in the hotels' area.

\section{Regions A , C, E , F , G , H , I , J}

In Maihama, Kairaku, Tomioka, Mihama, Tekkodon, Imagawa, Irifune and Chidori regions, we detect variant deformation patterns that can be caused by soil liquefaction (Fig. 10.e). These results confirm well with the field surveys conducted by KRDB and JGS (Fig. 10.c), Tokimatsu et al., (2012) (Fig. 10.b) and Urayasu city government (Fig. 10.d). 


\subsection{Conclusions}

In this paper, we present our approach to estimate deformations due to soil liquefaction phenomenon, which was developed in several Japanese cities during the 2011 Tohoku earthquake. We propose generating single-master coseismic stack of interferograms using a postseismic SAR image as master and a stack of preseismic SAR images as slaves. This interferogram structure facilitate the PS-InSAR analysis in the presence of major shock deformation, in addition, it allows a prompt estimation of the liquefaction deformation by utilizing the SAR images archives with only one postseismic SAR image.

In this approach, we use the interferogram stack to identify the reliable pixels in the study area (PSs) using phase stability analysis, and then we estimate and remove the preseismic mean velocity and DEM error components. Finally, we isolate the liquefaction effects using least squares inversion and spatial phase filtering. In order to assess the accuracy of the proposed approach, quantitatively, we test it using synthetic data simulating the effects of the 2011 Tohoku earthquake. The estimated mean velocity, DEM error and local deformation show RMSE of $1.68 \mathrm{~mm} /$ year, $0.73 \mathrm{~m}$ and $5.23 \mathrm{~mm}$, respectively.

Then, we estimate and present the liquefaction deformation in Urayasu city, Japan using 18 ALOS-PALSAR images. A qualitative assessment of the final results shows a good agreement with a damage and inclination maps generated by field surveys. We detect a coseismic ground subsidence in Higashina region, which cause the buildings to subside and tilt. We also detect a coseismic ground subsidence in the region of the Hilton and Sheraton Grande Tokyo bay Hotels ranges from $-2 \mathrm{~cm}$ to $-4 \mathrm{~cm}$.

It is worth mentioning that, the proposed approach gives an accurate qualitative measurement of the damage severity of structures, on the other hand, the quantitative accuracy of the deformation measurements depends on the density of the identified PS pixels and the accuracy of the phase unwrapping process, which is a classical problem in PS-InSAR analysis.

\section{Acknowledgment}

We are grateful to the Japan Aerospace Exploration Agency, JAXA for providing the ALOS-PALSAR data. We acknowledge the Kanto Regional Development Bureau of the Ministry of Land, Infrastructure, Transport and Tourism (KRDB) and the Japanese Geotechnical Society (JGS) for providing soil liquefaction data.

\section{References:}

Burgmann, R., Rosen, P. A., \& Fielding, E. J. (2000). SYNTHETIC APERTURE RADAR INTERFEROMETRY TO MEASURE EARTH'S SURFACE TOPOGRAPHY AND ITS DEFORMATION. Annual Review of Earth and Planetary Sciences, 169-209.

Bhattacharya, S., Hyodo, M., Goda, K., Tazoh, T., \& Taylor, C. (2011). Liquefaction of soil in the Tokyo Bay area from the 2011 Tohoku (Japan) earthquake. Soil Dynamics and Earthquake Engineering, 16181628.

Buckley, S. M., Rosen, P., Hensley, S., \& Tapley, B. (2003). Land subsidence in Houston, Texas, measured by radar interferometry. JOURNAL OF GEOPHYSICAL RESEARCH, VOL. 108, 8-1:8-12.

Costantini, M., \& Rosen, P. (1999). A Generalized Phase Unwrapping Approach for Sparse Data. Geoscience and Remote Sensing Symposium. 1, pp. 267 - 269. Hamburg: IEEE.

ElGharbawi, T., \& Tamura, M. (2014, February). Measuring deformations using SAR interferometry and GPS observables with geodetic accuracy: Application to Tokyo, Japan. ISPRS Journal of Photogrammetry and Remote Sensing, 88, 156-165.

Ferretti, A., Prati, C., \& Rocca, F. (2000). Nonlinear subsidence rate estimation using permanent scatterers in differential SAR interferometry. IEEE TRANSACTIONS ON GEOSCIENCE AND REMOTE SENSING, VOL. 38(No. 5), 2202 - 2212. 
Ferretti, A., Prati, C., \& Rocca, F. (2001). Permanent scatterers in SAR interferometry. IEEE TRANSACTIONS ON GEOSCIENCE AND REMOTE SENSING, VOL. 39(No. 1), 8 - 20.

Goldstein, R. M., \& Werner, C. L. (1998). Radar interferogram filtering for geophysical applications. GEOPHYSICAL RESEARCH LETTERS, 25(21), 4035-4038.

Goldstein, R. M., Engelhardt, H., Kamb, B., \& Frolich, R. M. (1993). Satellite Radar Interferometry for Monitoring Ice Sheet Motion: Application to an Antarctic Ice Stream. SCIENCE, VOL.262, 1525-1530.

Guarnieri, A., \& Prati, C. (1997). SAR Interferometry: A “Quick and Dirty” Coherence Estimator for Data Browsing. IEEE TRANSACTIONS ON GEOSCIENCE AND REMOTE SENSING, VOL. 35(NO. 3), 660-669.

Hanssen, R. (2001). Radar Interferometry: Data Interpretation and Error Analysis. Dordrecht: Kluwer Academic Publishers.

Hooper, A., Segall, P., \& Zebker, H. (2007). Persistent scatterer interferometric synthetic aperture radar for crustal deformation analysis, with application to Volcan Alcedo, Galapagos. JOURNAL OF GEOPHYSICAL RESEARCH, VOL. 112, B07407.

Imakiire, T., \& Kobayashi, T. (2011). The Crustal Deformation and Fault Model of the 2011 off the Pacific Coast of Tohoku Earthquake. Bulletim of the Geospatial Information Authority of Japan, 59, 21-30.

Ishihara, K. (2012). LIQUEFACTION IN TOKYO BAY AND KANTO REGIONS IN THE 2011 GREAT EAST JAPAN EARTHQUAKE. International Symposium on Engineering Lessons Learned from the 2011 Great East Japan Earthquake, (pp. 63-81). Tokyo, Japan.

Ishitsuka, K., Tsuji, T., \& Matsuoka, T. (2012). Detection and mapping of soil liquefaction in the 2011 Tohoku earthquake using SAR interferometry. Earth Planets Space, 1267-1276.

Kampes, B. M. (2005). Displacement parameter estimation using permanent scatterer interferometryy, Ph.D. thesis. Delft,Netherlands.: Delft University of Technology.

Kanto Regional Development Bureau of Ministry of Land, I. (2011). Investigation of soil liquefaction in Kanto region associated. (http://www.ktr.mlit.go.jp/) or (http://www.jiban.or.jp/) (in Japanese).

Liu, G., Buckley, S. M., Ding, X., Chen, Q., \& Luo, X. (2009). Estimating Spatiotemporal Ground Deformation With Improved Permanent-Scatterer Radar Interferometry. IEEE TRANSACTIONS ON GEOSCIENCE AND REMOTE SENSING, VOL. 47(NO. 8), 2762-2772.

Lyons, S., \& Sandwell, D. (2003). Fault creep along the southern San Andreas from interferometric synthetic aperture radar, permanent scatterers, and stacking. JOURNAL OF GEOPHYSICAL RESEARCH, VOL. 108(NO. B1), 2047.

Massonnet, D., Feigl, K., Marc, R., \& Adragna, F. (1994). Radar interferometric mapping of deformation in the year after the Landers earthquake. Nature, VOL. 369, 227-230.

Mora, O., Mallorqui, J. J., \& Broquetas, A. (2003). Linear and Nonlinear Terrain Deformation Maps From a Reduced Set of Interferometric SAR Images. IEEE TRANSACTIONS ON GEOSCIENCE AND REMOTE SENSING, VOL. 41(NO. 10), 2243-2253.

Paige, C. C., \& Saunders, M. A. (1982). LSQR: An Algorithm for Sparse Linear Equations and Sparse Least Squares. ACM Transactions on Mathematical Software, Vol. 8(No. 1), 43-71. 
Perissin, D., \& Wang, T. (2012). Repeat-Pass SAR Interferometry With Partially Coherent Targets. IEEE TRANSACTIONS ON GEOSCIENCE AND REMOTE SENSING, VOL. 50(NO. 1), 271-280.

Tamura, M., \& Li, W. (2013). Detection of Soil Liquefaction Areas in the Kantou Region using Multi-temporal InSAR Coherence. Asia-Pacific Conference on Synthetic Aperture Radar, (p. TH3.R1.3). Tsukuba, Japan.

Tokimatsu, K., \& Katsunata, K. (2012). LIQUEFACTION-INDUCED DAMADE TO BUILDINGS IN URAYASU CITY DURING THE 2011 TOHOKU PACIFIC EATHQUAKE . International Symposium on Engineering Lessons Learned from the 2011 Great East Japan Earthquake, (pp. 665674). Tokyo, Japan.

Tokimatsu, K., Tamura, S., Suzuki, H., \& Katsumata, K. (2012). Building damage associated with geotechnical problems in the 2011 Tohoku Pacific Earthquake. Soils and Foundations, Volume 52(Issue 5), 956-974.

Tsukamoto, Y., Kawabe, S., \& Kokusho, T. (2012). Soil liquefaction observed at the lower stream of Tonegawa river during the 2011 off the Pacific Coast of Tohoku Earthquake. Soils and Foundations, 987-999.

Williams, S., Bock, Y., \& Fang, P. (1998). Integrated satellite interferometry: Tropospheric noise, GPS estimates and implications for interferometric synthetic aperture radar products. Journal of Geophysical Research: Solid Earth, Vol. 103 (no. B11), 27051-27067.

Yamaguchi, A., Mori, T., Kazama, M., \& Yoshida, N. (2012). Liquefaction in Tohoku district during the 2011 off the Pacific Coast of Tohoku Earthquake. Soils and Foundations, 811-829.

Yasuda, S., Harada, K., Ishikawa, K., \& Kanemaru, Y. (2012). Characteristics of liquefaction in Tokyo Bay area by the 2011 Great East Japan Earthquake. Soils and Foundations, 793-810.

Zhang, L., Ding, X., Lu, Z., Jung, H.-S., Hu, J., \& Feng, G. (2014). A Novel Multitemporal InSAR Model for Joint Estimation of Deformation Rates and Orbital Errors. IEEE TRANSACTIONS ON GEOSCIENCE AND REMOTE SENSING, VOL. 52(NO. 6), 3529-3540. 